\title{
Case study on the recent solid waste management scenario in Rajshahi city, Bangladesh
}

\author{
Md. Nobinur Rahman ${ }^{1,}$, Mohammad Ahmeduzzaman ${ }^{2}$ \\ ${ }^{1}$ Department of Civil Engineering, Rajshahi University of Engineering \& Technology, Rajshahi, Bangladesh \\ ${ }^{2}$ Department of Civil Engineering, Stamford University Bangladesh, Dhaka, Bangladesh
}

\section{Email address:}

mnrahmanruet@gmail.com(M. N. Rahman),maz060086@gmail.com(M. Ahmeduzzaman)

\section{To cite this article:}

Md. Nobinur Rahman, Mohammad Ahmeduzzaman. Case Study on the Recent Solid Waste Management Scenario in Rajshahi City, Bangladesh. American Journal of Environmental Protection. Vol. 2, No. 2, 2013, pp. 58-63. doi: 10.11648/j.ajep.20130202.15

\begin{abstract}
A healthy life, cleaner city and a better environment are the logical demands for the city dwellers. The Rajshahi City Corporation was considered as 'Dustbin free city' because of the past state of the environment of the city. But in the recent times, it has been difficult to say it because of the lack of the proper knowledge about the waste management and the unmanaged implementation of rules and regulations during the process of management. The study has been carried out on the present state of solid waste management condition of the Rajshahi City Corporation. It has been found that total 170 tons of solid wastes of different type are being generated daily. The responsibility of the management is of them is mostly an authority in community system and a few on the house owner. Of the total quantity 40-50 percent is collected efficiently and the rest is left. It is broadly estimated that between 10-15 percent of the total municipal budget is used for solid waste management corresponding to approximately Tk. 20/- per capita each year. Moreover, surprisingly the number of cleaners per thousand populations in Rajshahi is nearly 1.0. Waste densities (350 to $450 \mathrm{Kg} / \mathrm{m} 3$ ) and moisture contents (50\% to $70 \%$ ) by weight are much higher than that of the wastes in industrialized countries. The solid waste of Rajshahi generally has a high organic content $(60 \%$ to $70 \%)$ and a low proportion of combustible matter. The wastes, which remain uncollected, are dumped in open spaces, street and drains, clogging the drainage system, which create serious environmental degradation and health risks. The collected waste is presently being disposed off mainly in a low-lying area about 3 kilometers from the corporation area. In Rajshahi, wastes, which have market value, are being reclaimed or salvaged for recycling. The unmanaged solid waste should be collected and managed properly and the authority should be more concerned about that feature for making the city healthiest and livable.
\end{abstract}

Keywords: Solid Waste Management, Recycling, Rajshahi City Corporation, Organic Matter, Dustbin Free City

\section{Introduction}

Solid wastes are all the waste arising from human and animal activities that are normally solid and are discarded as useless or unwanted. Economic development, urbanization and improving living standards in cities, have led to an increase in the quantity and complexity of generating waste. Rapid growth of population and industrialization degrades the urban environment and places serious stress on natural resources, which undermines equitable and sustainable development. Solid waste can be categorized as the recyclable materials, toxic substances, compostable organic matters and soiled wastes [1]. Inefficient management and disposal of solid waste is an obvious cause of degradation of the environment in most cities of the developing world. The environment and human health face a severe impact due to the unscientific disposal of solid waste [2].

Municipal corporations of the developing countries are not able to handle increasing quantities of waste and a significant portion of wastes are not properly stored, collected or disposed in the proper places for ultimate disposal due to lack of enthusiasm, consciousness, loyalty, as well as money [3]. There is a need to work towards a sustainable waste management system, which requires environmental, institutional, financial, economic and social sustainability. In less developed Asian countries integrated management and safe disposal of Municipal Solid Waste can be found in reference [4].

Most appropriate systems for collection, storage and transportation and choice of a suitable method for disposal, sustainable management programs and proper planning is 
entirely depends on the characteristics of municipal solid waste [5]. The study has been conducted to fulfill several objectives as mentioned follows.

- To conduct a feasibility study on solid waste collection and transportation system of the Rajshahi City Corporation.

- To visualize the present status of solid waste collection and transportation system of the Rajshahi City Corporation.

- To identify the problems of solid waste collection and transportation system.

- To recommend the possible way to recover these problems.

\section{Study Area}

Rajshahi, the map shown in Fig. 1, one of the divisional cities of Bangladesh, is expanding rapidly turning it into a mega city with an enormous growth of population. Solid waste is being generated at a faster pace, posing a serious management threat. The rapid growth of industries, lack of financial resources, inadequate trained manpower, inappropriate technology and lack of awareness of the community are the major constraints of solid waste management for the fast growing metropolis of Rajshahi. A healthy life, cleaner city and a better environment are the logical demands for the city dwellers as the municipality is traditionally funded for solid waste services from the municipal tax system for waste collection and disposal. Due to limited finances and organizational capacity, it has been really difficult for the municipality to ensure efficient and appropriate delivery of solid waste collection and disposal services to the entire population.

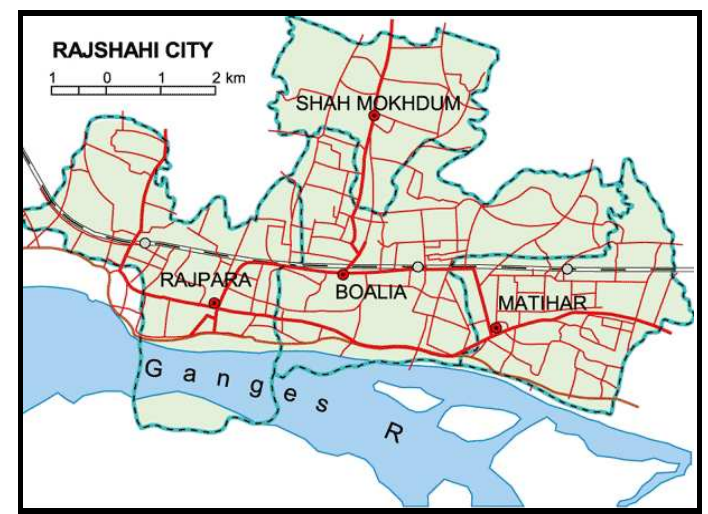

Figure 1. Study area

\section{Methodology}

The methodology of this survey consists of practical field observation and field based data collection of solid waste generation, collection, transportation of solid waste management situation through structured and non-structured questionnaire and formal and non-formal interviews. The relevant secondary data for this study was collected from published and unpublished sources. The survey was, therefore, undertaken to explore the nature and many other habitation problems and different reason of the environmentally hazardous situation of water supply, sanitation and solid waste management system in Rajshahi City. The overall work to be done is described schematically by the flow chart showing in the Fig. 2.

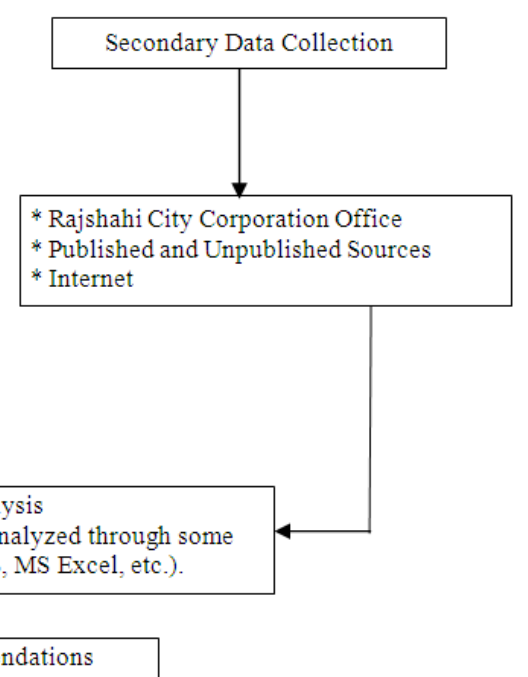

Figure 2. Flow chart research methodology

\subsection{Data Collection}

A study was undertaken to assess the environmental conditions e.g. solid waste generation, collection, transportation solid waste management etc of Rajshahi City Corporation, and to identify the deficiencies for the improvement of existing situation. In order to achieve the objectives a comprehensive literature review, household surveys and field visits, and a questionnaire survey was conducted. 'Household head' means the person who plays the main role in the decision-making process of a family. In the absence of the household head, the second important 
adult member of the family was interviewed. A questionnaire survey was also conducted upon 100 respondents of the Rajshahi City Corporation.

\subsection{Survey Form}

It is observed from the surveys that solid waste management situation in the study areas are not satisfactory. Moreover, the other services like sanitation, drainage and waste disposal are not adequate and needs improvement in those areas. However, the questionnaire survey forms has the information about occupation, income level (monthly), family members, house ownership, responsibility of sanitation, per capita waste generation classified according to the income level, type of solid waste generation etc.

\section{Results}

\subsection{Solid Waste Generation}

Per capita solid waste generation is significantly depends on the different income level with different living standard of cities. Fig. 3 shows that the monthly income level of the people living in Rajshahi city. Only 7\% people in Rajshahi city which have monthly income greater than BDT 30000 on the other hand a major group of people (28\%) having monthly income less than BDT 5000. Fig. 4 shows the variation of the per capita solid waste generation in residential areas in Rajshahi city with respect to different income level.

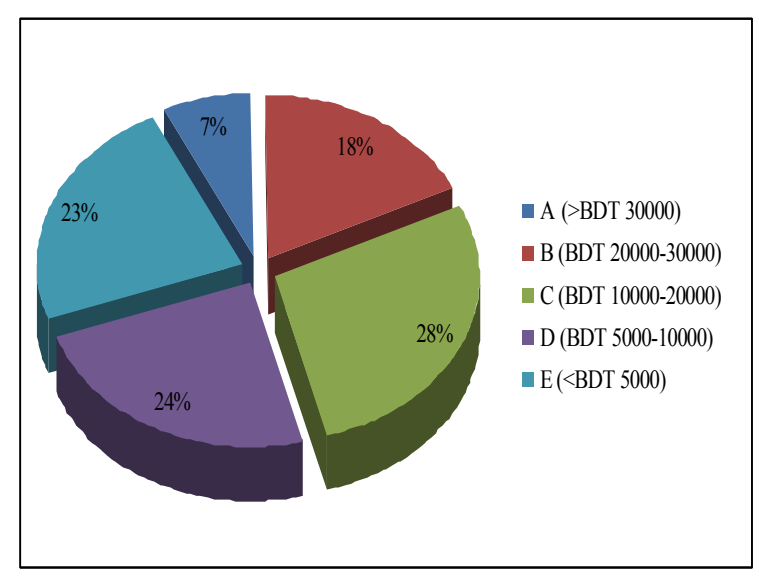

Figure 3. Monthly income level of the people in Rajshahi City

It can be seen that the higher income level family produces higher amounts of per capita waste generation $(0.34 \mathrm{Kg}$ /day) whereas the lower income level family produces $0.23 \mathrm{Kg}$ solid waste per day per capita. The mean solid waste generation rate in residential areas in Rajshahi city obtained as $0.29 \mathrm{~kg} /$ capita/day for different income level with different living standard.

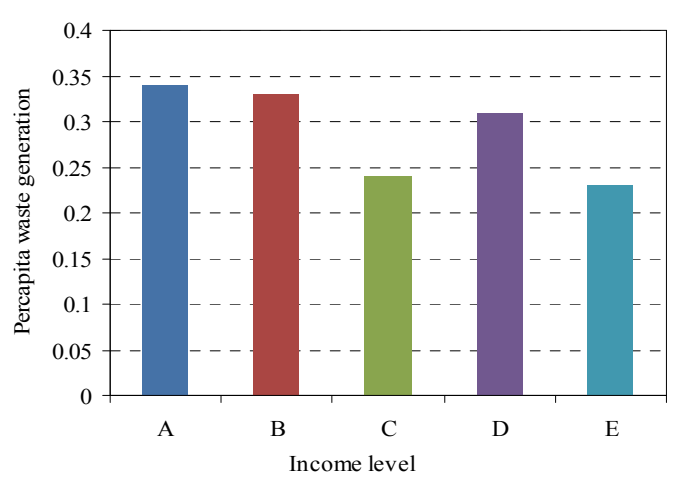

Figure 4. Per capita waste generation (Kg/day) with respect to different income level

Fig. 5 shows the composition of solid waste generated in Rajshahi city. One of the major compositions of generating solid waste is food and vegetable waste which is almost $70 \%$ of total waste generation (ton/day). The generated solid waste also contains paper products, plastics, rubber, textile and leather, metal glasses, garden wastes and many other materials. Among all of this composition rock, dirt and metal glasses are found in a slighter amount (3\%). In Rajshahi city, residential sectors contribute $78.6 \%$ waste in total generation of solid waste. From the Fig. 6 it can be seen that commercial sectors and institutional sectors contribute $17.7 \%$ and $1.3 \%$ waste in total generation of solid waste in the Rajshahi city respectively.

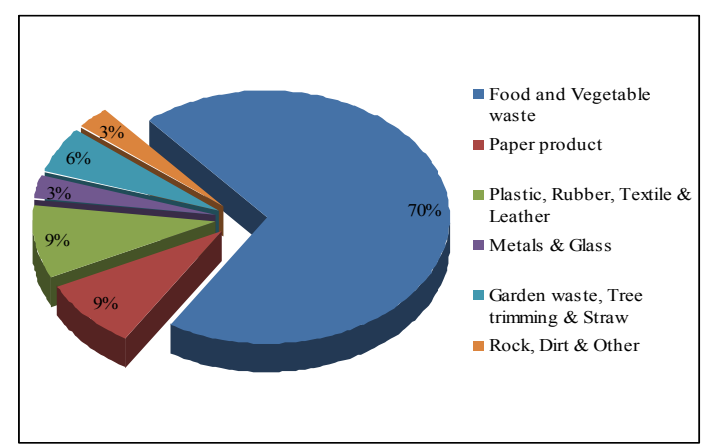

Figure 5. Composition of solid waste generated in Rajshahi

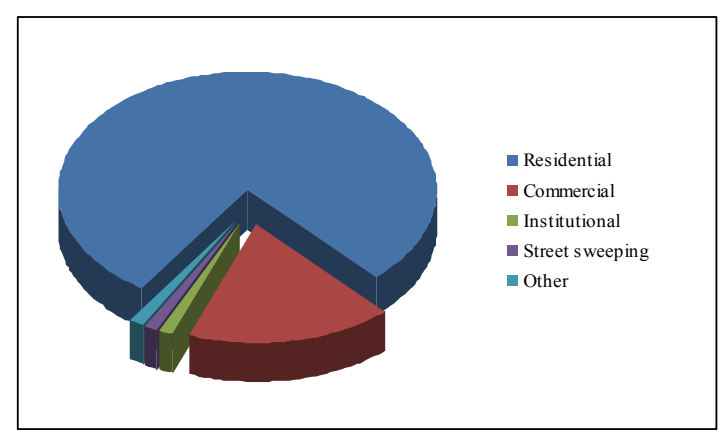

Figure 6. Different sectors to contribute the generation of solid waste

\subsection{Solid Waste Collection}

Collection of un-separated and separated solid waste in an urban area is difficult and complex because the generation of 
residential and commercial-industrial solid waste takes place in every home, every apartment building, and every commercial and industrial facility as well as on the streets, parks, event vacant areas. The Rajshahi City Corporation is considered as 'Dustbin free city'. There are 30 wards in the Rajshahi City Corporation. Fifteen wards are covered by 'door to door waste collection' facilities. At an initial stage all wastes collected between 5:00 AM and 1 PM from all points at which waste is generated and the conservancy department of RCC is responsible for the secondary waste collection to remove waste from its dustbins and transport it to the final disposal sites. Besides any waste left at any important place must be collected immediately by RCC concern authority [6]. Rajshahi City Corporation (RCC) is trying to provide this service to all the wards in the near future. There are one dumping site (3.5 feet deep in 15.98 acre area) and 35 secondary collection points. Fig. 7 and Fig. 8 showing the waste collection of RCC by open truck and manually driven rickshaw respectively.

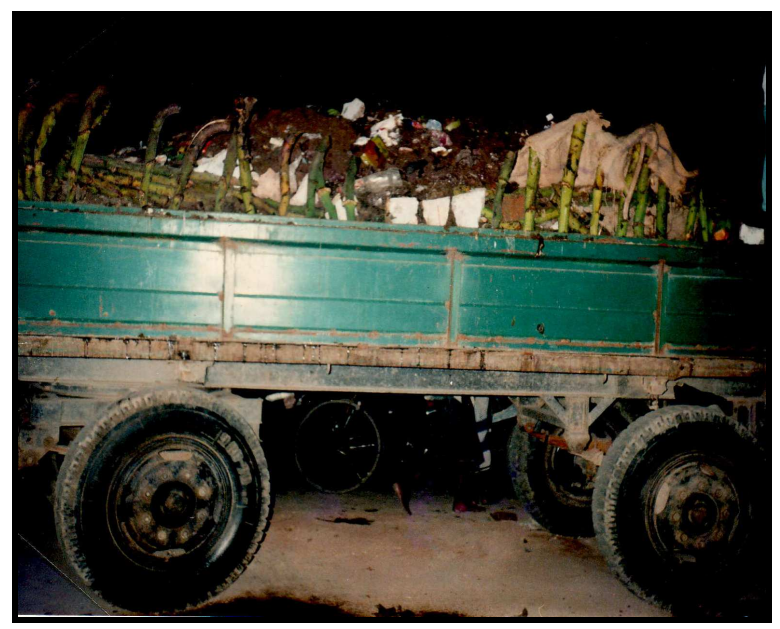

Figure 7. Waste collection by open truck of RCC

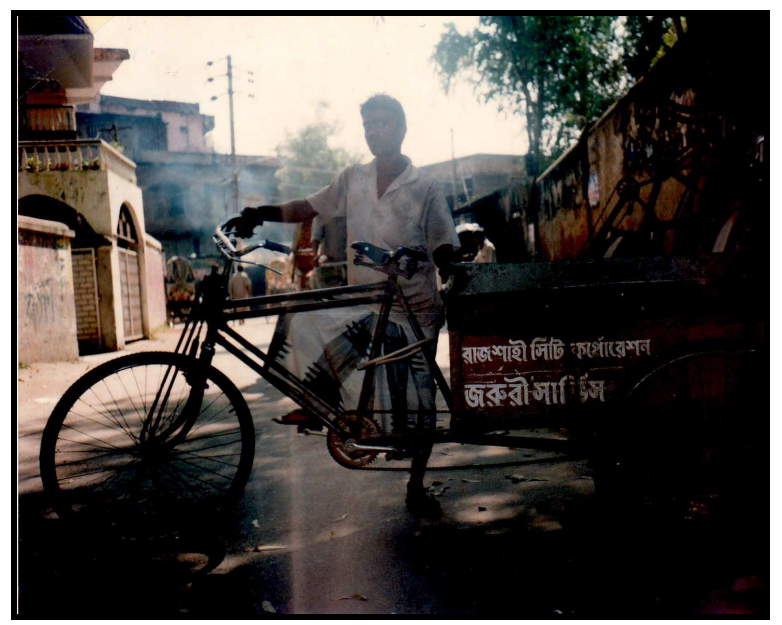

Figure 8. Manually driven rickshaw used waste collection

\subsection{Solid Waste Transportation}

Transformation processes used to alter the form of the waste and to recover useful products. About 70 to 80 percent of the total cost are used for transfer and transportation work of solid waste. Waste materials that have been source separated must be collected or gathered together before they can be recycled. The principle methods now be used for the collection of these materials include curbside collection using a specially designed collection vehicle and delivery by homeowners to drop-off and buyback centers. The functional element of transfer and transport refers to the means, facilities, and appurtenances used to affect the transfer of wastes from relatively small collection vehicles and to larger vehicles and to transport them over extended distances to either processing centers or disposal sites. Usually Rajshahi City Corporation sweepers take the waste by truck or Rajshahi City Corporation's special small rickshaw van collect medical wastes from few hospitals/clinics. The present number of trucks, rickshaws and wheelbarrows in the RCC are 12, 216 and 150 respectively (RCC). Fig. 9 shows that the current number of available vehicles that are used to transport solid waste to disposal sites at the Rajshahi City Corporation (RCC).

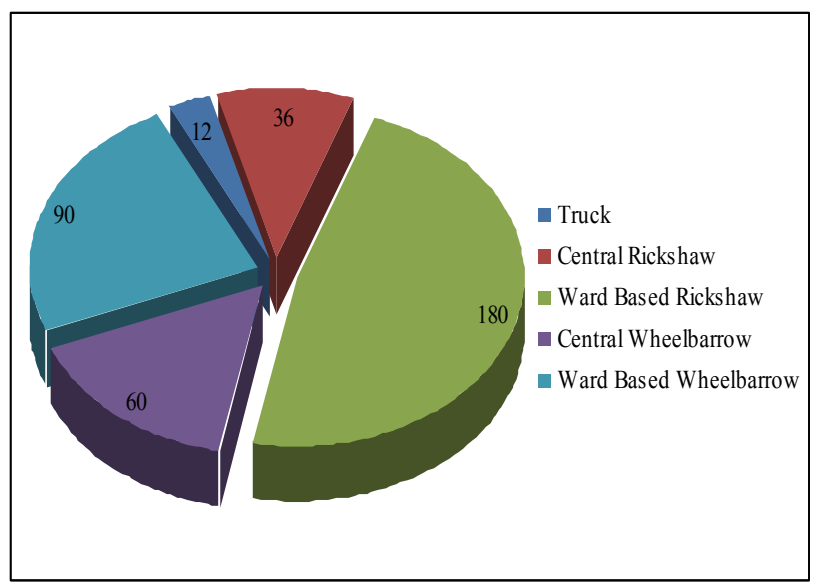

Figure 9. Total number of vehicles used to transport solid waste

\subsection{Solid Waste Disposal}

In many developing countries, the common practice to dump solid waste in open, uncontrolled and poorly managed landfill sites which cause dreadful conditions in the environment. In many cities of Bangladesh, the waste are being disposed of in an open land in an insufficient manner. The collected solid waste is presently being disposed off mainly in a low-lying area named "Naodapara" about 3 kilometers from the corporation area. This disposal site does not follow the principle of sanitary landfills. In this disposal site, waste spreads all over the site. There is no proper system to maintain the landfill area. With the blowing of wind there is an unpleasant odor spread all over the disposal area. Compaction, leveling of waste and final covering by earth are rarely observed at a Naodapara disposal site in Rajshahi city. The hospital waste that is generally generated from various hospitals located in city corporation area are incinerate on the Rajshahi Medical Hospital immediately. The wastes which are not burnable that are dumped under 
the ground. The solid waste disposal site of the Rajshahi City Corporation is shown in Fig. 10.

However, instead of having all these drawbacks in the system, the new light of hope is that, recent cutting edge research is being done for solid waste management. More environmental friendly landfill site with necessary liner as well as a sophesticative leachate collector is being thought to install into the site. Although some clinics and hospitals have their own waste management plant, rest of all are also being forcely induced to adopt that by the authority.

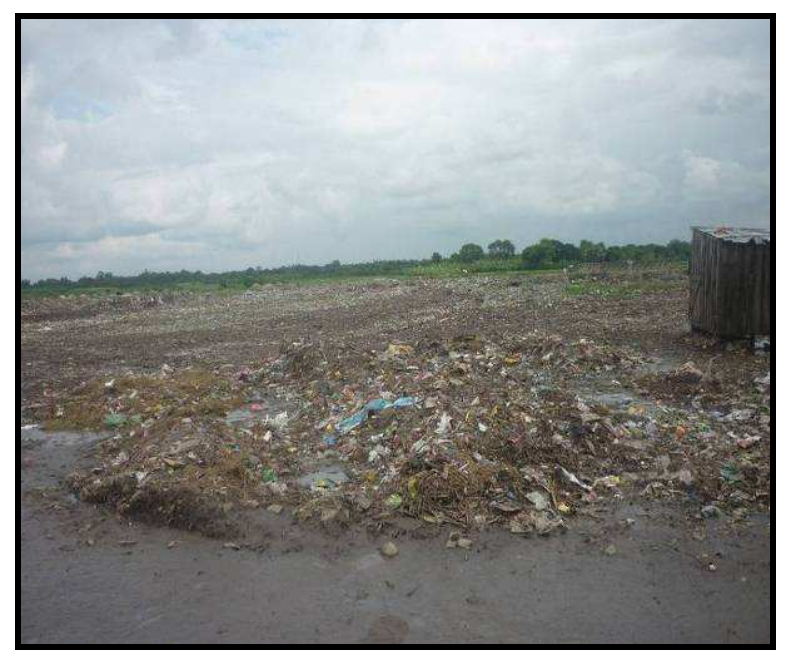

Figure 10. Solid waste disposal site of RCC

\section{Discussion}

Rajshahi City Corporation is the one of the organizations responsible for waste management in an area of $48 \mathrm{sq} . \mathrm{Km}$. with a population of 0.5 million. The waste generated in this area is estimated to be around 150 to 200 tones every day. Of this quantity $40-50$ percent is collected efficiently and the rest is left. It is broadly estimated that between $10-15$ percent of the total municipal budget is used for solid waste management corresponding to approximately Tk. 20/- per capita each year. The number of cleaners per thousand populations in Rajshahi is nearly 1.0. Waste densities (350 to $\left.450 \mathrm{Kg} / \mathrm{m}^{3}\right)$ and moisture contents $(50 \%$ to $70 \%)$ by weight are much higher than that of the wastes in industrialized countries. The solid waste of Rajshahi generally has a high organic content $(60 \%$ to $70 \%)$ and a low proportion of combustible matter.

Communities have arranged house-to-house collection of garbage by their own initiatives and efforts (about $80 \%$ are community based house to house collection system). Street sweeping is done manually and debris is loaded from the kerb-side into the handcarts and delivered to the street storage facilities. In the downtown areas, where the roads and lanes are narrow, the wastes are transported by two types of trucks i.e. either flat-bedded open vehicles or trucks with closed bodies (with shutters that slide vertically on both sides). Every vehicle has its own designated areas and routes for collecting waste. The wastes, which remain uncollected, are dumped in open spaces, street and drains, clogging the drainage system, which create serious environmental degradation and health risks. The collected waste is presently being disposed off mainly in a low-lying area about 3 kilometers from the corporation area. In Rajshahi, wastes, which have market value, are being reclaimed or salvaged for recycling. Recycling contributes to resource conservation as well as environmental protection.

\section{Conclusion and Recommendations}

A healthy life, cleaner city and a better environment are the logical demands for the city dwellers. The Rajshahi City Corporation is considered as 'Dustbin free city'. But it is difficult to say right now. Authority of Rajshahi City Corporation should to look on proper management of generated waste. Need implementation laws and regulations in the proper way. Need to upgrade the concept of solid waste management and improve the system of entire management.

The following recommendations need to be made for improvement of the collaborative program-

- Public awareness of health education should be raised through public campaigns.

- Monitoring facilities have to improve.

- Proper implementation of laws and regulations.

- Have to improve collection and transportation equipments.

- Modification of municipal ordinance is needed to accommodate the inclusion of NGOs, CBOs, and micro enterprises into the main stream of Solid Waste Management.

- Public awareness of waste segregation, recycling and reuse should be raised through public campaigns and media demonstrations through NGOs.

- The Municipality should facilitate innovative, community-based programs rather than capital-intensive projects.

\section{Acknowledgements}

The author would like to show his gratitude and thankful acknowledgement to the authority of the Rajshahi City Corporation and others who helped perform the study.

\section{References}

[1] Jha, M.K., Sondhi, O.A.K., Pansare, M., "Solid waste management - a case study. Indian Journal of Environmental Protection, 23 (10), 1153-1160, 2003.

[2] Rathi, S., "Alternative approaches for better municipal solid waste management in Mumbai, India," Journal of Waste Management, 26(10), 1192-1200, 2006.

[3] Ahsan, A., Alamgir, M., Islam, R., Chowdhury, K.H., "Initiatives of Non-Governmental Organizations in Solid Waste Management at Khulna City" In: Proc. 3rd Annual Paper Meet and Intl. Conf. on Civil Engineering, IEB, Dhaka, Bangladesh, pp: 185-196, March $9-11,2005$. 
[4] Alamgir, M., McDonald, C., Roehl, K.E., Ahsan, A., Eds., "Integrated Management and Safe Disposal of Municipal Solid Waste in Least Developed Asian Countries" Final Report of 'WasteSafe', a feasibility project under the Asia Pro Eco Programme of the EC, Department of Civil Engineering, Khulna University of Engineering and
Technology, Bangladesh, 2005.

[5] Alamgir, M., Ahsan, A., "Municiple Solid Waste and Recovery Potential: Bangladesh Perspective," Iran. J. Environ. Health. Sci. Eng., 4 (2), 67-76, 2007.

[6] Rajshahi City Corporation. http://www.erajshahi.gov.bd 